\title{
Application of Contest Driven Didactics in Major Courses of Package Engineering Specialty
}

\author{
Yingzhe XIAO ${ }^{1, a}$, Dejian $\mathrm{ZHAO}^{1, \mathrm{~b}}$ and Yong $\mathrm{XIE}^{* 1, \mathrm{c}}$ \\ 1 School of Packaging and Materials Engineering, Hunan University of Technology, China \\ a32260771@qq.com, b124613185@qq.com, c1143166575@qq.com
}

${ }^{*}$ Corresponding author name

\begin{abstract}
Keywords: package system design, contest driven didactics, air-dropping package without parachute.

Abstract. It is difficult to meet the requirement of practical ability training goal in package engineering specialty with only traditional didactics focused on theoretic lectures. Thus, we introduced "contest driven" didactics in practical teaching sections such as projects of packaging system design course and curriculum design, in order to promote learning by contest. In this paper, we introduce the teaching effect of designing contest on the topic of "package design of egg air-dropping without parachute from low altitude". The rationality and scientificity of creative structure design in student work is analyzed, and the mode of thinking and typical design misunderstanding in students' package design practice under extreme protection requirements are pointed out. On this basis, we proposed a contest driven didactic with "design - experiment - contest" as key elements, to help students to establish system engineering design consciousness, and to improve their comprehensive design ability.
\end{abstract}

\section{Introduction}

In recent years, the quality of higher education has gone worse and worse, especially presented as graduated students cannot meet the requirements of social and economic development in current training mode. Simultaneously, with the intensification of the market competition in the packaging industry, the modern packaging enterprises have put forward higher requirements for the packaging higher education. New requirements and expectations are proposed for the graduated students majored in packaging engineering. For the employing units, the most valued talent quality and ability are mainly concentrated in engineering students' abilities in engineering, self-learning, and innovation[1]. Therefore, the teaching quality in higher education is urgently needed to be improved, and the students are required to have comprehensive professional ability in the intense competition environment of employment.

It is of great practical significance to cultivate the students' ability of independent thinking and innovation. The basic requirement of cultivating innovative and practical talents is that students should be able to select proper projects according to their own interests, thinking and researching independently during the process of solving the problems or completing the tasksin order to cultivat students' open thinking, and thus to improve students' innovation ability.

\section{Introduction of "contest driven" didactics in classroom teaching}

Learning, especially the learning of college students', is not only a process of accumulating knowledge, experience, and ability, but also a creative learning process[2]. The traditional one-way knowledge-feeding teaching makes classroom teaching become a mere formality, the students' learning atmosphere is boring, which leads to greatly reduction the effectiveness of learning. This phenomenon is greatly related with the traditional teaching concept. For a long time, we model the traditional education idea as preaching, teaching, and answering. The teaching mode is " teachers to teach \& students to listen", the teachers are the center of the class, and the students accept passively. Teachers read textbooks or PPT text, and students staring blankly in the classroom, and boning up in reciting before the exam. In this case, it is impossible to develop students' comprehensive application 
ability. At the same time, in the digital and information society, knowledge and information update and spread throughout the internet leading the two sides of teaching and learning to get access to information in similar degree, which makes students feel the traditional classroom not essential.This also restricts the teaching quality and teaching achievement[3].

In recent years, the task driven learning model, which is also known as "task-based learning", has been widely concerned by the public. . This learning model is to set up learning activities in the real environment, so that learners complete the real tasks to achieve the purpose of learning related knowledge. So this learning model is based on task driven[4]. Through this learning model, we can improve students' learning initiative, adjust and reorganize the existing knowledge structure. Students can test and improve their practical ability by completing tasks, thus greatly improve the efficiency of learning.

Students are the main body in the competition driven project task teaching. By transforming the knowledge into tasks, students take part in the competition, and changed the traditional one-way communication of knowledge. It is helpful for the students to form a positive, active learning attitude, and to emphasize competition and cooperation. Both "teaching" and "learning" are important in this process, and the students need tolearn both independently learning and cooperatively. This can make the most of teachers' leading rold and the students' role of importance. It breaks the old framework of the traditional teaching and changes the passive learning into active participation. The constant encouragement of teachers can further stimulate students' enthusiasm and interest in learning, which is in line with the principles of instructional design of construction doctrine theory[5].

Specific to the system design course of packaging engineering specialty, "contest driven" teaching method is to construct a teaching platform of "contest driven", using the task driven teaching method, design competition, arrangement competition environment, and then let the students participate in the challenge of the design project in the form of the competition team[6].

\section{The Implementation process of "contest driven" project teaching method}

After two years' practice, in the packaging Engineering Department of Hunan University of Technology, after two years' teaching practice, we attempt to use the, introduce competition mechanism, in the "packaging system design" curriculum design, according to the young students' psychology characteristics. We use the project titled "package design of egg airdrop without parachute from low altitude", to carry out the task-teaching in the form of group competition, and achieved satisfactory teaching result.

\section{Implementation process.}

\section{(1) Assign a mission for contest.}

The design task in this course is to design a packaging system of boxed egg products as disaster relief supplies, which is to propose complete packaging solutions for a package of 6 eggs, tomeet the requirements of helicopter airdrop without parachute from low altitude no less than 20 meters. The design content includes the demand analysis, the overall plan localization, the packing protection plan design, the sales packing design, the transportation packing design, the packing economy analysis and the project evaluation. Design requirements are mainly: (1)Internal and external packaging should be inclusive and protective, to maximize the using function of the product; (2) To select reasonable packaging materials with moderate price and common to be found in the market; (3)The packaging structure is reasonable, and fast in assembing and easy to operate; (4) The goods can be scientificly and reasonably in stacked in warehouse and transportation with neccesary stacking strength and stacking height; (5) Packaging can withstand any external incentives in the logistics process; (6) Consider environmental protection requirements and end consumer demand.

\section{(2) Group design and experiment}

The design and experiments are carried out in groups. Students are required to first complete the draft design, including the selection of material in various parts, structural design, sketching, and giving material selection reasons by written reports. Then to design the draft plan for the experiment and write a report including the name of the project, the required sample, the required experimental 
equipments, experimental principles, methods, procedures, and purpose. Finally, each group completes their experiments in the laboratory, and the design scheme can be adjusted and modified according to the progress of experiments. Samples for contest were produced after the completion of the experiments.

\section{(3) Airdrop contest}

Low altitude airdrop contest of 15 metres were successfully completed. 20 teams out of 49 succeeded to keep all 6 eggs intact, while there are also very few groups got all eggs broken. Follow on normal contest, some of the teams achieved perfect protection of all 6 eggs from the height of 20 meters, and there is one team even succeeded in the challengefrom the height of 25 meters.

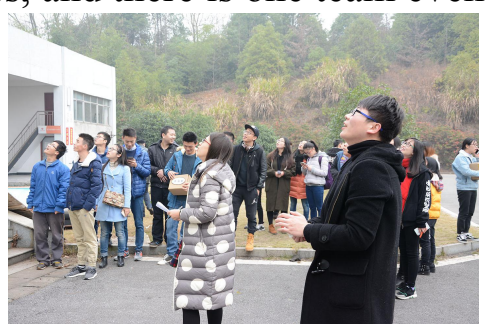

\section{(4) Defending}

The winning teams need to take part in the class defense summary. PPT report and questions answering were used to show their design works. The members of the winning teams were able to explain their design work, including the design ideas, design process, the experimental process, failure and success experience, showing the students' ability to express and teamworking.

\section{Analysis of contest works}

In the process of teaching practice, there have been many excellent works. They can reflect the considerable innovative awareness of students in the contest driven model. The examples are as follows.

\section{(1) Case 1: full paper material design}

Corrugated cardboard box using corrugated board type B with model number 0427 was used as the packaging box, ; and corrugated board type $\mathrm{E}$ was used as internal material, which was rolled in a tube to enhance the contact area with the eggs. Due to the good performance of corrugated cardboard with UV shape, the buffer structure is designed into a shape of letter "M" using corrugated board type B to protect the eggs from high altitude drop without damage. The packing process is simple. First, put the eggs into the corrugated board tube with a single layer; separate the eggs with corrugated tissues and seal the end of the tube; then, insert the tube with eggs into the "M" shaped buffer structure; finally, put them into the packing box.

The advantages of this design include small volume, easy in transportation and stacking; simple packaging process, convenient to open; excellent protection to the eggs, which meets the requirements of the low altitude airdrop in disaster relief.

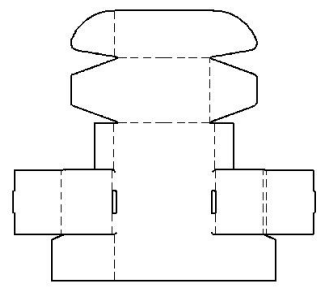

(a) the unfolding structure;

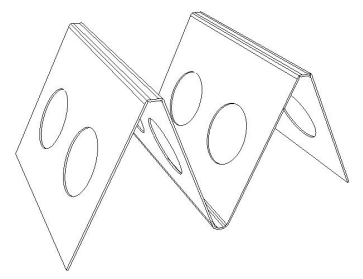

(b) "M" buffer structure;

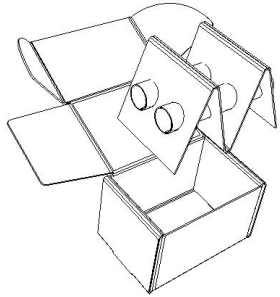

(c) the packing box of the Fig. 2 full paper material design sketch map

\section{(2) Case 2: mixed material design}

Corrugated cardboard box using corrugated board type B with model number 0427 was used as the packaging box, corrugated board type B was used as internal partition board. Special buffering material of pearl cotton (EPE) was used due to its good shockproof performance, using circular arch 
structure with outstanding shockproof effect. Largers arches were placed in each of the four directions, with a smaller arch to connect two larger arches. The inner hexagonal structure can firmly protect the eggs from being damaged when falling from high altitude. In the packaging process, the eggs were put into the middle of the EPE buffering material, then each of the buffering structure was separated by a partition board, and finally, they were put into the packing box.

The design is easy to transport, easy to open, easy to take the eggs out, and to protect the eggs in the low altitude airdrop conditions
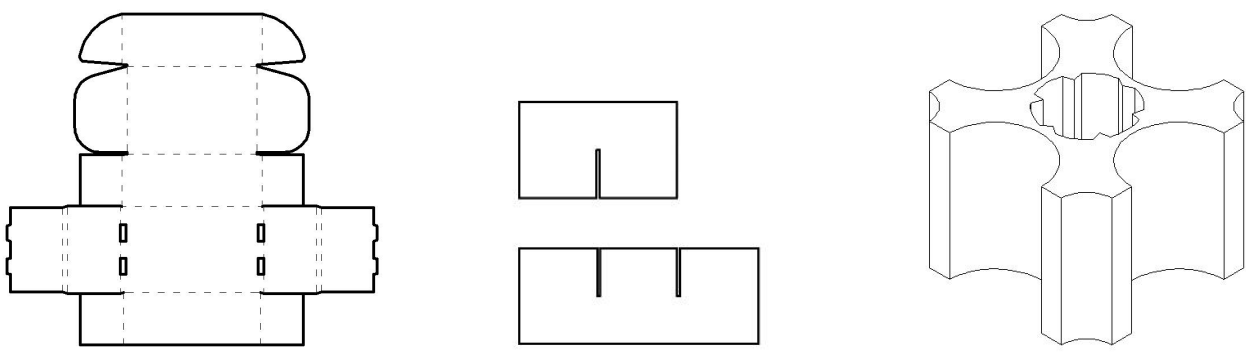

(a) the unfolding structure; (b) inner baffle structure; (c) EPE single buffer structure

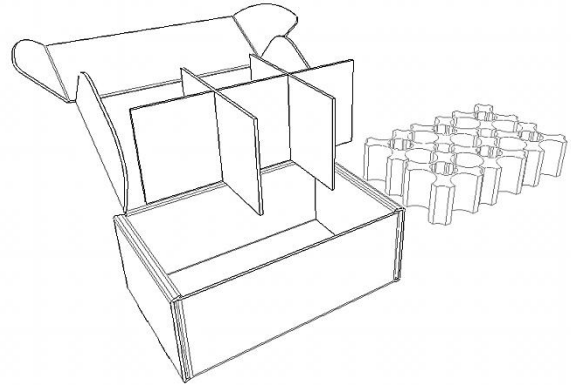

(d) the schematic diagram of each part;

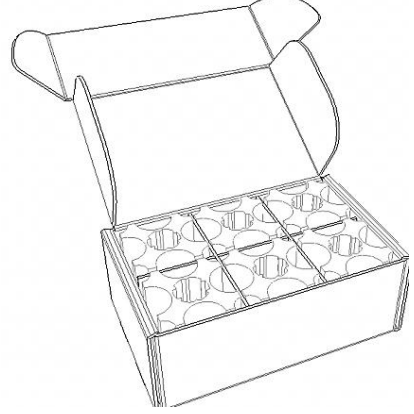

(e) the packing box of the egg

Fig. 3 mixed material design sketch map

\section{The enlightenment and problems brought by the contest driven teaching method}

It has been two years since the contest driven teaching method was introduced into the course "packaging system design" in packaging engineering major. In addition to the curriculum design project using tasks and contests, smaller projects and tasks are also carried out in large assignment and summary discussion in this course. Students act as the center of the course, we emphasis "learning in practice". Intense debates and task competitions are encouraged between groups, to fully arouses the students' enthusiasm for learning and the sense of competition, and promotes the cultivation of students' autonomous learning, cooperative learning and comprehensive application ability. The inspirations from this method include:

(1) Contest driven teaching method can fully present the concept of "student centered" and "learning in practice", which is in line with the trend of modern pedagogy.

(2) As a kind of non-intellectual factors closely related to teaching and learning, academic emotion plays an important role in the growth and development of students[7]. Students' self-cognition, achievement goal and cognitive ability are closely related to their academic emotions[8]. Contest driven teaching method provides a platform for students to show themselves and find themselves. It combines the contest mode with the learning practice to create the external conditions to improve students' academic emotions. This helps to develop and cultivate students' learning strategies, innovative ability, competitive ability and the ability to solve practical problems.

(3) Contest driven teaching can fully mobilize the enthusiasm of students to participate in activities, effectively stimulate students' interest and motivation to learn packaging.

(4) The contest driven teaching method can effectively cultivate students to establish the consciousness of system engineering design by the guidance and activity design of teacher, and the participation of students. 
At the same time, there are still many problems to be paid attention to:

(1) We should pay attention to the students' thinking mode and design errors in the practice of packaging design with protection requirements in the extreme conditions, and guide them in time. For the thinking mode, the students attention will mainly focus on effective protections due to the extreme conditionsOther requirements, such as the systematicness, the overall assessment requirements, manufacturing process requirements, and human efficacy requirements, were usually ignored until the assessment time. The designing is likely to be worse than expected. The design errors mainly focus on:1)Equivalenting packaging system design to packaging structure design; (2) Over depending the choice of buffer material itself, such as a variety of foam, while ignoring or even evade structural buffering design; (3)Taking the protection of eggs from broken as the ultimate goal of the design as long as the realization of the egg is not broken, while ignoring the assembling, coordination, aesthetics and other related factors for the whole packaging.

(2) It takes a lot of spare time in the design and preparation of teaching tasks, for both teachers and students. So, the teachers' responsibility and students' motivation to learn are particularly important. In order to improve the ordering and effectiveness of the open experiment, students need teachers' timely guidance. It worth further considering in how to effectively coordinate and guide students to avoid wrong path.

(3) Different from the discussion teaching in class, when the teachers tutoring the students one-on-one according to their different designs, we need to prevent student from cheating of design plan of other teams, which may lead to an unfair competition. This is another topic for teachers to guide students.

(4) The learning ability, design ability, practice and innovation ability of students in a team are different. There is no leader in some of the teams, teams members with poor speciality foundation or introverted personality cannot effectively carry out activities, which will lead to the poor quality of their task. More attention from teachers is needed in this case.

(5) The design of contest driven teaching should fully reflect the principles such as reality, progressive, operational, fun and competitive, as far as possible to complete the whole teaching activities in an orderly and effective manner.

The teaching practice has proved that the contest driven teaching method is a kind of effective teaching method which is worth popularizing. It is suitable for the teaching of all professional courses.

\section{Conclusion}

Colleges and universities should provide professional applied talents in a high level to the society. Packaging engineering students will play a pivotal role in the packaging enterprises after their graduation, and they will promote the development of the packaging industry greatly[9][10]. Contest driven teaching method emphasizes students' subjective position. Through the contest, the students take the initiative to participate in teaching activities, and mobilize the enthusiasm of students at different levels. This is helpful for the development of innovative, innovative professionals, so as to provide a talent pool in building the innovative country. With the development of requirement of the society and enterprises to the higher education, there will also be higher requirements in the reform and innovation of the classroom teaching. On this basis, the undergraduate teaching could also get a rapid development.

\section{References}

[1] Hou Huaiyin; Wang Junlin. The Process, Progress and Trends of University Teaching Method Research in the Mainland since Reforming and Opening: Journal of Higher Education. Vol. 35, no. 10 (2014), p. 63-71. In Chinese.

[2] Ma Huixia. The development of General Academic Emotion questionnaire for College Students: Chinese Journal of Clinical Psychology. Vol. 16, no. 6(2008), p. 594-596. In Chinese. 
[3] Fan Ying. The exploration and practice of task based teaching in College English Teaching under contest driven: Journal of Beijing Police Academy. no. 6(2014), p. 107-112. In Chinese.

[4] Tang Zhanhong. Research on the application of contest task driving method in the teaching of computer specialty in Higher Vocational Colleges: Journal of Higher Education. no. 9(2015), p. 48,50. In Chinese.

[5] Xie Jiaxin. Exploration and practice of " contest teaching method" in the computer teaching in Vocational School: Vocational and technical education (Teaching). Vol. 27, no. 14(2006), p. 86-87. In Chinese.

[6] Diansheng Chen; Zhen Li and Tianmiao Wang. Exploration and practice: A competition based project practice teaching mode: Mechatronics. Vol. 24(2014), p. 128-138.

[7] $\mathrm{Xu}$ Dingru. Study on the influence of competitive teaching method on basic nursing experimental teaching: Chinese medicine guide. Vol. 11, no. 13(2013), p. 772-773. In Chinese.

[8] Xu Xiancai; Gong Shaoying. Academic emotions and its influencing factors: Advances in Psychological Science. Vol. 17, no. 1(2009), p. 92-97. In Chinese.

[9] John Blewitt. Higher education for a sustainable world: Education + Training. Vol. 52(2010), p. 477-488.

[10]Dongjie Niu; Dahe Jiang and Fengting Li. Higher education for sustainable development in China: International Journal of Sustainability in Higher Education. Vol. 11(2010), p. 153-162. 